\title{
A Study on the Prevalence and Source of Staphylococci and Methicillin-resistant Staphylococcus aureus Causing Superficial Incisional Surgical Site Infection
}

\author{
Kameran M. Ali ${ }^{1}$ and Bahrouz M. A. Al-Jaff ${ }^{2}$ \\ ${ }^{1}$ Department of Medical Lab Technology, Kalar Technical College, Sulaimani Polytechnic University, \\ Kalar, Kurdistan Region - F.R. Iraq \\ ${ }^{2}$ Department of Biology, College of Education, University of Sulaimani, \\ Sulaimani, Kurdistan Region - F.R. Iraq
}

\begin{abstract}
Staphylococcus aureus and coagulase-negative staphylococci (CoNS) are common causatives of superficial incisional surgical site infection (SSI). The source of the pathogens is still not fully diagnosed whether it is endogenous or exogenous particularly with regard to the extent of its resistance to antibiotics. Therefore, this study is designed to determine the rate of infection, the source of pathogens, and the extent of their resistance to antibiotics. For this purpose, pre-, intra- and post-operative swabs from the nasal and skin of patients undergoing surgeries and samples from the hospital environment have been collected and processed for isolation and identification of staphylococci. Bacterial analysis and antibiotic susceptibility profiles of the isolates are assessed by unweighted pair group method with arithmetic mean (UPGMA) analysis based on random amplified polymorphic DNA-polymerase chain reaction (RAPD-PCR) and disc diffusion test for antibiotics susceptibility profile. The microbiological and PCR results indicate that SSIs are found in 113/512 (22.07\%), Staphylococcus spp. rated 67/512 (13.09\%) of infections. Further analysis indicates that $\mathrm{S}$. aureus, CoNS, and both of them were causes SSI with different rates 41/67 (61.2\%), 23/67 (34.3\%), and 3/67 (4.5\%), respectively. Results of RAPD-PCR for 70 isolates reveal that $52 / 70(74.28 \%)$ of SSIs are from endogenous source, followed by $10 / 70(14.29 \%)$ and $8 / 70(11.43 \%)$ from hospitals acquired and undetermined sources, respectively. Moreover, results of antibiotic susceptibility test reveal that $24 / 44$ (54.5\%) of isolates belong to methicillin-resistant Staphylococcus aureus; from both endogenous and exogenous sources with 13/24 (54.17\%) and 11/24 $(45.83 \%)$, respectively.
\end{abstract}

Index Terms-Methicillin-resistant Staphylococcus aureus, Source of Infections, Staphylococcus spp., Surgical site infection.

ARO-The Scientific Journal of Koya University Volume IX, No.1 (2021), Article ID: ARO.10752, 08 pages DOI:10.14500/aro.10752

Received: 16 November 2020; Accepted: 22 June 2021

Regular research paper: Published: 30 June 2021

Corresponding author's e-mail: kameran.m.ali@spu.edu.iq

Copyright (C) 2021 Kameran M. Ali, Bahrouz M. A. Al-Jaff. This is an open-access article distributed under the Creative Commons Attribution License.

\section{INTRODUCTION}

Surgical site infection (SSI) is a common postsurgical nosocomial infection that occurs at the operation site. It increases the occurrence of morbidity and mortality, leading to increased health-care costs through extended hospitalization times and the emergence of antimicrobial resistance in pathogens (Mangram et al., 1999). The Center for Disease Control and Prevention has classified SSIs as either incisional or organ/space infections. SSIs are further categorized into superficial (affecting skin and subcutaneous tissues, or deep (attacking deeper soft tissues) (Horan et al., 1992).

There are several risk factors related to SSI, including age, nutritional status, smoking, obesity, preexisting infection, diabetes and other chronic diseases, blood transfusion, prolonged hospitalization (either pre- or post-operative), poor surgical technique, prolonged duration of surgery, and inadequate sterilization of surgical instruments (Cheadle, 2006; Owens and Stoessel, 2008). Aside from the inoculum of contaminant bacteria introduced into the incision either during or after the operation, the microenvironment and the immunological integrity of the host have importance in determining the severity of infection (Medeiros et al., 2005).

Bacteriological studies have shown that SSIs are usually caused by endogenous and/or exogenous bacteria that enter the operative wound either during or after surgery (Owens and Stoessel, 2008; Dancer et al., 2012; BerríosTorres et al., 2017). The most commonly isolated bacteria in SSIs are Staphylococcus aureus and coagulase-negative staphylococci (CoNS) (Anderson and Kaye, 2009; Pal et al., 2019; Dohmen, 2006), which frequently colonize the skin and nares in the healthy population, and in pre-operative patients are associated with an elevated risk of SSI (Dohmen, 2006). In general, patients who are nasal and skin carriers of staphylococci are 2-9 times more likely to develop an SSI, and it has been shown that $85 \%$ of SSIs can be traced to endogenous colonization of the patients (Skråmm et al., 2014). Although the isolated bacteria from SSI depending on 
the surgical procedures, whereas the problem is that some of them are resistant to antibiotics, particularly methicillinresistant Staphylococcus aureus (MRSA), which increase the incidence of SSIs (Bhattacharya et al., 2016). The widespread use of broad-spectrum antibiotics leads to emergence of antimicrobial resistant strains in hospitals. The problem is more complicated in developing countries as a result of poor infection control practices, overcrowded hospitals, and inappropriate use of antimicrobials (Negi et al., 2015).

In spite of the comprehensive techniques and careful surgical procedures used to control infections, the rate of staphylococcal SSI remains a real threat in surgical settings (Mawalla et al., 2011). Therefore, it is important to identify whether the source of bacterial pathogens (Staphylococcus spp.) isolated from patients with post-operative SSI is the patients' skin or contaminated items existent in the hospital environment (Reichman and Greenberg, 2009).

Determining the sources of SSI is a crucial avenue of research in remedying these problems and finding solutions to minimize the threat of SSI. However, there is to date no standardized diagnostic method for SSI infection and often no post-discharge surveillance system in place (WHO, 2016). The incidence rate of SSI has not yet been established in Kurdistan Region of Iraq. Therefore, this study aims to use various diagnostic methods to determine the rate and the source of bacterial SSIs, and to assess the risk of these causative agents through testing their antibiotic susceptibility profiles.

\section{MATERIALS AND METHODS}

\section{A. Sampling and Data Collection}

A hospital-based cross-sectional study was conducted from August 2018 to July 2019 in three surgical centers of hospitals (Kalar General Hospital, Life Private Hospital and Sheray Naqib Hospital) in the Kalar city, Kurdistan, Iraq. A total of 512 patients (233 males, 279 females, and ages 9-67 years) who had undergone surgeries were followed up for staphylococcal superficial incisional SSIs until they had fully recovered or were discharged from the hospital. Nasal and skin swabs were taken aseptically from patients on admission to the hospital and after operation completion from subcutaneous wounds. Swabs were also taken from elements within the hospital environment, including the instruments and disinfectants used for each patient. Clinical data were obtained from the patients' files and by physical examination using structured and pretested questionnaires.

The patients who underwent surgery were continuously monitored for signs and symptoms of SSI during hospital admission and after discharge (follow-up on an outpatient basis) for 30 days of surveillance. Sterile cotton swabs were collected aseptically from superficial surgical wounds of each patient suspected of having SSI before the injury was cleaned with antiseptic. Swabs were obtained from the surgical sites while avoiding contamination by skin commensals and transported immediately to the molecular biology lab of Garmian University for processing by standard laboratory procedures (Elmer et al., 1997).

\section{B. Isolation and Identification of Causative Agents}

For isolation and preliminary identification, specimens were streaked on 5\% sheep blood agar and mannitol salt agar, and then incubated for $24 \mathrm{~h}$ at $37^{\circ} \mathrm{C}$. In case no bacterial growth, the plates were further incubated for $24 \mathrm{~h}$ more. Then, after $48 \mathrm{~h}$ the specimens with no growth, they were reported as negative. Identification at the species level depended on colony morphology, Gram's staining, and conventional biochemical tests including catalase test, coagulase test, and detection of hemolysin activity (Forbes et al., 2007).

\section{Molecular Identification by PCR}

Identifications were confirmed by PCR using specific primers for each Staphylococcus species. The target genes have been selected for each species. Then, species-specific primers were designed using Primer-BLAST on NCBI. Finally, all primers were BLAST analyzed before they were synthesized by Macrogen Inc. (Seoul, Korea).

\section{DNA extraction}

Extraction of DNA from clinical isolates was performed according to the kit manufacturer's instructions (Geneaid Biotech Ltd., New Taipei City, Taiwan). Concentration and purity (260/280 ratio) of the extracted DNA was checked by NanoDrop (Thermo Scientific, Waltham, MA, USA).

\section{Multiplex PCR}

$S$. aureus was detected using single PCR. However, CoNS detection was carried out in two sets of multiplex PCR as previously described by Kim et al., 2018. For this purpose, a pair of universal primers was added to each set of multiplex assays for the identification of CoNs species. 16S rRNA sequencing was used for the identification of isolates that were not detected by the PCR sets that mentioned in Table I.

PCR amplification reactions were carried out with $10 \mu \mathrm{l}$ of MasterMix and $2.5 \mu \mathrm{l}$ of template DNA for a final volume of $20 \mu \mathrm{l}$ in a single pathogen tube, using a Gradient Thermocycler (Eppendorf, Germany). The protocol used included an initial denaturation at $95^{\circ} \mathrm{C}$ for $5 \mathrm{~min}$, followed by 35 cycles of denaturation at $95^{\circ} \mathrm{C}$ for $30 \mathrm{~s}$, primer annealing for $30 \mathrm{~s}$, primer extension at $72^{\circ} \mathrm{C}$ for $45 \mathrm{~s}$, and the final extension at $72^{\circ} \mathrm{C}$ for $5 \mathrm{~min}$. The primer sequences, multiplex sets, concentrations, annealing temperature, and calculated lengths of the corresponding amplicons are listed in Table I.

\section{Determination the Source of Causative Staphylococci Using Random Amplified Polymorphic DNA-polymerase Chain Reaction (RAPD-PCR) and UPGMA Analysis}

Randomly amplified polymorphic DNA analysis by PCR (RAPD-PCR) was performed for genotyping of $S$. aureus and CoNS, and to ascertain the source of infection by comparing them with each other. The RAPD-PCR reaction was performed using 10-mer primers 5'-AGCGTCACTG-3' (Casey et al., 2006), 5'-GCGATCCCCA-3', 5'-AGCGTCACTG-3', and 5'-TGACCCGCC-3' (Pereira et al., 2002). The reaction was carried out in a $20 \mu \mathrm{l}$ reaction volume containing $10 \mu \mathrm{l}$ 
TABLE I

LIST OF PRIMERS USED IN THIS STUDY

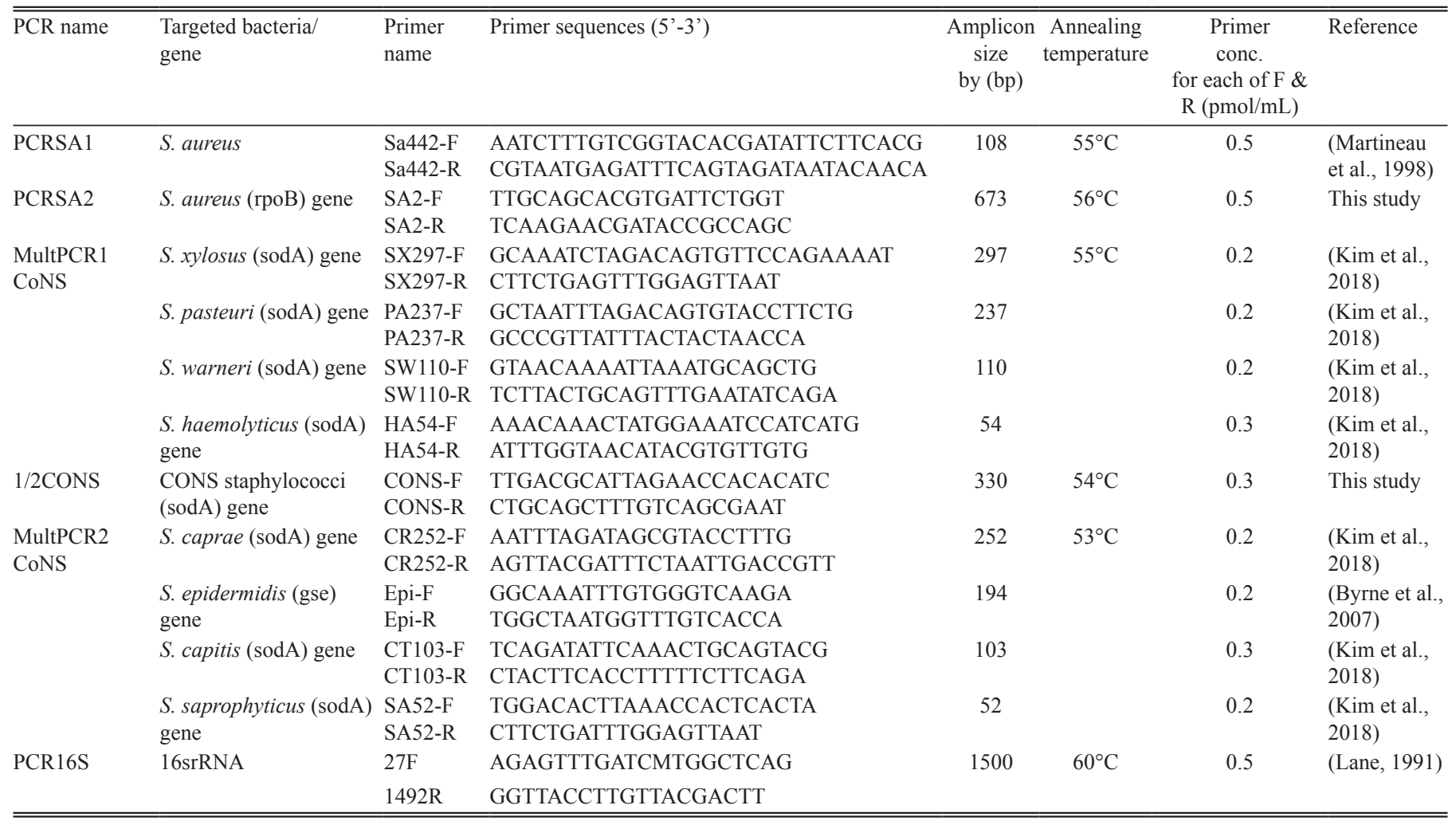

MasterMix, $1.2 \mu \mathrm{l}$ primers, $2.5 \mu \mathrm{l}$ DNA template, and 6.3 $\mu l$ sterile deionized water. The negative control for each primer contained all the components except template DNA. The amplification procedure was comprised of one cycle for $5 \mathrm{~min}$ at $94^{\circ} \mathrm{C}$, followed by 5 low-stringency cycles of $30 \mathrm{sec}$ at $94^{\circ} \mathrm{C}, 2 \mathrm{~min}$ at $20^{\circ} \mathrm{C}$, and $2 \mathrm{~min}$ at $72^{\circ} \mathrm{C}$, and 30 high-stringency cycles of $30 \mathrm{sec}$ at $94^{\circ} \mathrm{C}, 1 \mathrm{~min}$ at $32^{\circ} \mathrm{C}$, and $2 \mathrm{~min}$ at $72^{\circ} \mathrm{C}$. The amplification was concluded within $5 \mathrm{~min}$ at $72^{\circ} \mathrm{C}$. Then, $10 \mu \mathrm{l}$ of each product and $5 \mu \mathrm{l}$ of a 100 bp DNA molecular mass ladder (TransGen Biotech Co., Ltd., Beijing, China) were loaded into separate wells in a $2 \%$ agarose gel containing $5 \mu \mathrm{l}$ of safe dye and electrophoresed at $100 \mathrm{~V}$ for $1 \mathrm{~h}$ in $1 \%$ TBE buffer. The clearest and most reproducible bands were chosen for the determination of their presence or absence in each strain. Faint bands that could not be systematically visualized were not taken into account.

Typing of bacteria was used for monitoring pathogens and revealing the source of infection. The RAPD patterns were considered to be different when the profiles differed by at least one band (Burnie et al., 1997; Marsou et al., 2001). Here, we used RAPD-PCR followed by agarose gel electrophoresis for typing of isolates that were collected from pre-, during, and post-operative nasal, skin, and subcutaneous wound specimens of patients with SSI, as well as the hospital environment. The relationships among $S$. aureus and CoNS RAPD profiles were determined by unweighted pair group method with arithmetic mean (UPGMA) dendrogram cluster analysis (Addinsoft, 2020).

\section{E. Antibacterial Susceptibility Testing by Disc Diffusion Method (Kirby-Bauer Test)}

Antibacterial susceptibility testing of Staphylococci spp. was performed using the disc diffusion method on MüellerHinton agar medium (Oxoid, UK). The antibiotic discs with respective concentrations prescribed in the study area included the known six antibiotic classes (Oxoid, UK) and were selected as they used in testing resistance for nosocomial bacteria in addition to that mentioned in inpatients prescriptions in local hospitals and Clinical Laboratory Institute Standards (CLSI) guidelines (Wayne, 2017). The used antibiotics were penicillin $\mathrm{G}(10 \mathrm{IU})$, ampicillin $(10 \mu \mathrm{g})$, amoxicillin/ clavulanic acid $(20 / 10 \mu \mathrm{g})$, cephalothin $(30 \mu \mathrm{g})$, clindamycin $(15 \mu \mathrm{g})$, azithromycin $(15 \mu \mathrm{g})$, tetracycline $(30 \mu \mathrm{g})$, rifampicin (5 $\mu \mathrm{g})$, erythromycin $(15 \mu \mathrm{g})$, vancomycin $(30 \mu \mathrm{g})$, ceftriaxone $(30 \mu \mathrm{g})$, ciprofloxacin $(5 \mu \mathrm{g})$, levofloxacin $(5 \mu \mathrm{g})$, gentamycin $(10 \mu \mathrm{g})$, trimethoprim/sulfamethoxazole $(25 \mu \mathrm{g})$, amikacin $(30 \mu \mathrm{g})$, nitrofurantoin $(100 \mu \mathrm{g})$, imipenem $(10 \mu \mathrm{g})$, and meropenem $(10 \mu \mathrm{g})$. MRSA was identified using cefoxitin $(30 \mu \mathrm{g})$ and oxacillin $(1 \mu \mathrm{g})$ and interpreted according to CLSI guidelines (2017).

One to three colonies were picked up from a new pure culture and mixed aseptically in a test tube containing $3 \mathrm{ml}$ sterile saline to form a homogenous suspension. Turbidity of the suspension was adjusted to a $0.5 \mathrm{McFarland}$ standard using a photometric device (Densimat, BioMérieux). Within $15 \mathrm{~min}$, a sterile cotton swab was dipped into the bacterial suspension, excess fluid was removed, and the swab used to evenly streak the surface of Müeller-Hinton agar in three different planes, rotating the plates approximately $60^{\circ}$ each 
time. The rim of the plate was then swabbed once. After $5 \mathrm{~min}$, the selected antibiotic discs were placed aseptically on the surface of the inoculated media using sterile forceps. The plates were inverted and incubated aerobically at $35-37^{\circ} \mathrm{C}$ for 18-24 h, after which the mean radii diameters of the inhibition zone were measured in millimeters using calipers and interpreted using CLSI guidelines (Wayne, 2017). The standard reference strain S. aureus ATCC 25923 was used to assess the disc's quality. Multidrug resistance (MDR) was considered as resistance to at least one antibiotic in three or more antibacterial categories (Magiorakos et al., 2012).

\section{F. Ethics Statement}

The study was approved by the Ethical Committee of the Department of Medical Lab. Technology, Kalar Technical Institute, Sulaimani Polytechnic University, the Declaration of Helsinki regarding the ethical principles for medical research involving human subjects was considered. Patients' consent was acquired; for minors, guardians' consent was acquired.

\section{G. Statistical Analysis}

Statistical analysis was performed using the Statistical Package for the Social Sciences version 16.0 software program (IBM Corporation, Armonk, NY, USA) to determine associations of SSI incidence in patients. $P<0.05$ was considered as statistically significant. The incidence rate was expressed as the percentage of patients who acquired SSI among those admitted to surgical centers. Antibiotic resistance was expressed as the ratio between the numbers of isolates confirmed as resistant over the total number of isolates subjected to the antibiotic.

\section{RESULTS}

\section{A. Rate and Etiology}

Obtained results of molecular identification were exhibited that the SSI rate of those included in the study was $113 / 512(22.07 \%)$. The rate of staphylococcal SSI was $67 / 512(13.09 \%)$; infection by $S$. aureus occurred in $41 / 67$ patients $(61.2 \%)$, infection by CoNS occurred in $23 / 67(34.3 \%)$, and infection by both $S$. aureus and CoNS occurred in 3/67 (4.5\%), Table II. Most staphylococcal infections $(95.5 \%)$ were caused by a single species, with the remaining $4.5 \%$ caused by multiple species. Staphylococcus spp. were isolated from 29/67 male patients (43.3\%) and $38 / 67$ from female patients (56.7\%).

Among the 70 isolated staphylococci, 26 of them were CoNS species and they distributed as $17(65.38 \%)$ S. epidermidis, 4 (15.38\%) S. haemolyticus, 3 (11.54\%) S. capitis, and 1 (3.85\%) of each S. warneri and S. hominis.

\section{B. Determination the Source of Causative Agents Using RAPD-PCR and UPGMA Analysis}

RAPD typing for both $44 \mathrm{~S}$. aureus and 26 CoNS SSI isolates produced amplicons with a range of profiles. UPGMA analysis for $S$. aureus revealed three clusters, with 10 SSI
TABLE II

STAPHYLOCOCCUS SPP. ISOLATED IN THE SURGICAL SITE INFECTIONS

\begin{tabular}{lcc}
\hline \hline Bacterial species & Number of SSI (\%) & Total bacterial no. (\%) \\
\hline SSI patients with S. aureus & $41(61.19 \%)$ & $44(62.86 \%)$ \\
SSI patients with CoNS & $23(34.33)$ & $26(37.14 \%)$ \\
SSI patients with both S. aureus & $3(4.48 \%)$ & \\
and CoNS & $67(100 \%)$ & $70(100 \%)$ \\
Total &
\end{tabular}

isolates showing similarities in banding patterns to those of exogenous surgical ward isolates; the other isolates were determined to show non-similar patterns. The typing profile revealed that 29 infections were caused by endogenous $S$. aureus not related to surgical centers, Fig. 1. UPGMA analysis revealed that out of 26 CoNS isolates, 23 of them were similar to nasal and skin isolates of the same patients, revealing the endogenous source of the causative pathogens, all S. haemolyticus, S. warneri, and S. hominis isolates were sourced from the endogenous source, whereas two isolates of $S$. epidermidis and single isolate of $S$. capitis were appeared to be from the exogenous source, Fig. 2.

Regarding the source of Staphylococcus spp. causing SSI, UPGMA analysis revealed that 52/70 (74.28\%) were sourced from patients themselves (endogenous source), whereas $10(14.29 \%)$ were sourced from the hospital environment (exogenous source) and 8 (11.43\%) were from an undetermined exogenous source, Fig. 3a.

\section{Antibiotic Resistance Profile}

All staphylococci isolated from SSIs were resistant to at least one class of the antibiotics used; $68.6 \%$ of them were multiple drug resistant (MDR). Most of S. aureus and CoNS were resistant to penicillin $\mathrm{G}$ (95.5\% and $88.5 \%$, respectively), with moderate resistance to gentamicin, tetracycline, erythromycin, and trimethoprim/sulfamethoxazole. S. aureus showed higher resistance than CoNS to those drugs that mentioned above. MRSA was recorded in $54.5 \%$ of the isolated staphylococci; the majority of MRSA sources (13/24, $54.17 \%$ ) were the patients themselves, whereas the remainder $(11 / 24,45.83 \%)$ were exogenous or undetermined. About $20.5 \%$ of isolated MRSA were resistant to vancomycin. Out of 26 CoNS isolates, 5 (19.2\%) were resistant to methicillin: $S$. epidermidis (3), S. haemolyticus (1), and $S$. capitis (1). The resistance to the other antibiotics was variable. $S$. aureus and CoNS were highly susceptible to rifampicin, showing resistances to only $13.6 \%$ and $11.5 \%$, respectively. The susceptibility to nitrofurantoin was also high $(8.2 \%$ and $15.4 \%$ resistance, respectively), Table III.

Out of $44 \mathrm{~S}$. aureus SSI isolates, 10 had an antibiotic resistance profile with a high degree of similarity to that of a surgery environment isolate. Of the other 34 isolates, 29 of them showed profiles identical to those of the same patients' pre-surgical isolates, whereas the remaining 5 showed no similarity in profile to pre-surgical or environmental isolates. The antibiotic profile of 26 CoNS isolates revealed that 22 of them were identical to the same patients' pre-surgical isolates, whereas the other 4 showed no similarity in profile to pre-surgical and environmental isolates. 


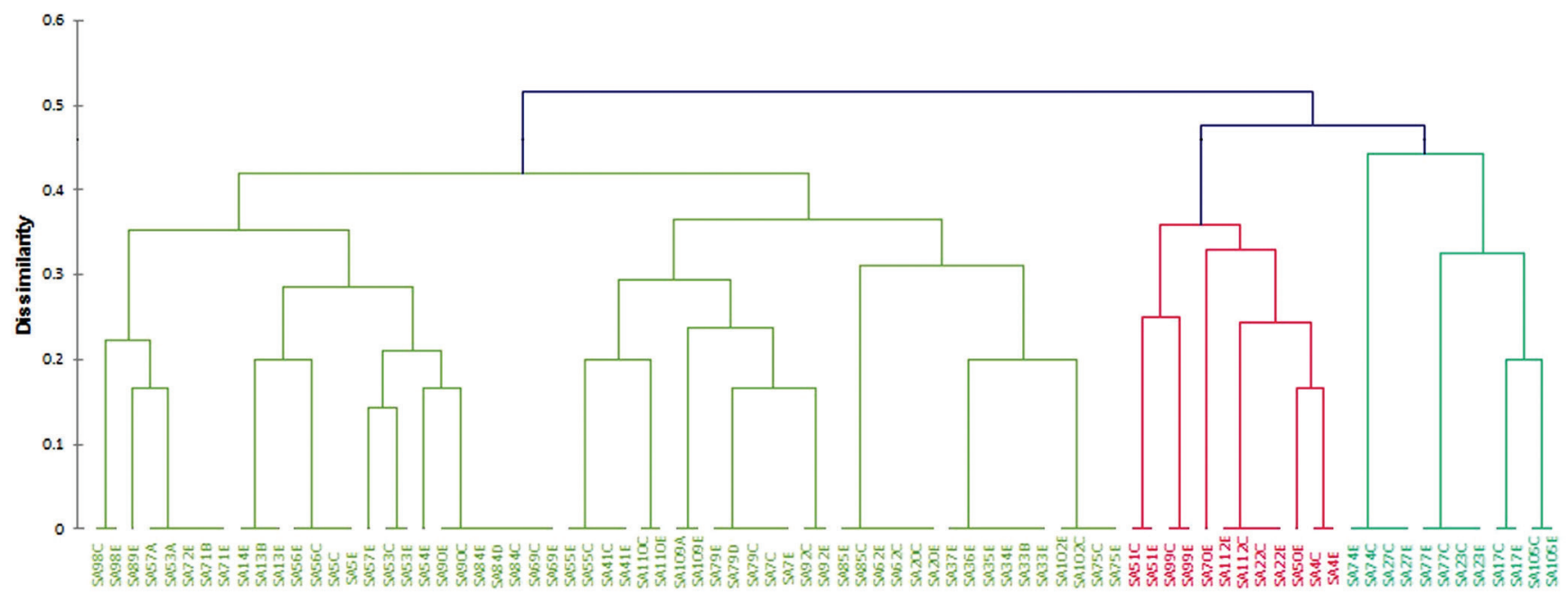

Fig. 1. UPGMA dendrogram analysis of RAPD profiles from SA isolates. SA: Staphylococcus aureus.

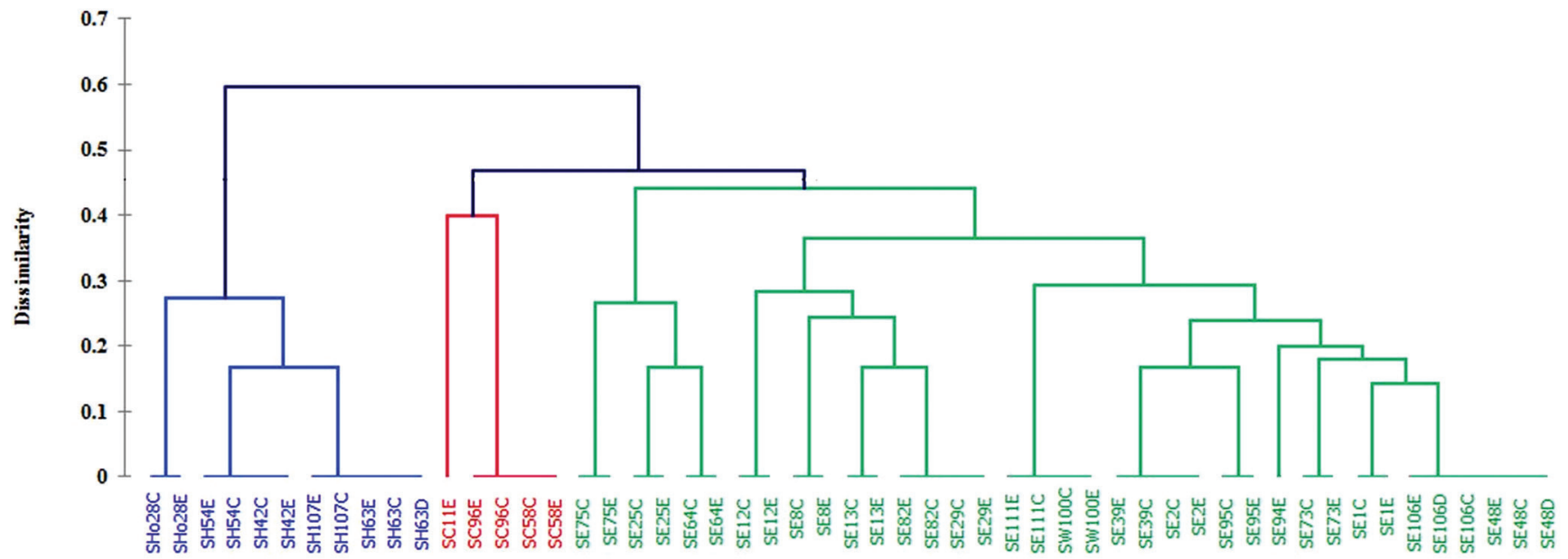

Fig. 2. UPGMA dendrogram analysis of RAPD profiles from CoNS isolates. SE: Staphylococcus epidermidis, SH: Staphylococcus haemolyticus, SC: Staphylococcus capitis, SHo: Staphylococcus hominis, SW: Staphylococcus warneri.

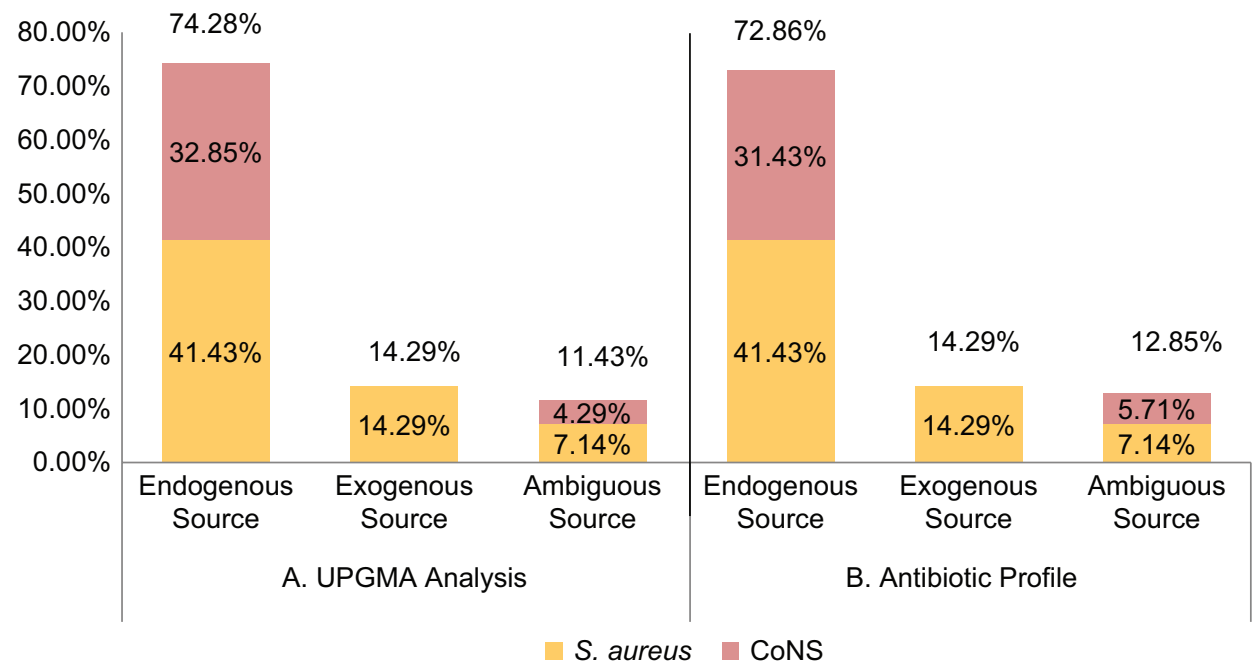

Fig. 3. The percentage of Staphylococcal Surgical Site Infections Source: (a) The source of staphylococcal SSI according UPGMA analysis; (b) the source of staphylococcal SSI according to antibiotic profile. 
TABLE III

ANTIBACTERIAL RESISTANCE PATTERN AMONG SSI STAPHYLOCOCCUS SPP. ISOLATES

\begin{tabular}{|c|c|c|c|c|c|}
\hline \multicolumn{2}{|c|}{ No. Antibiotic } & \multicolumn{2}{|c|}{$\begin{array}{c}\text { Resistant } \\
\text { Staphylococcus } \\
\text { aureus }(n=44)\end{array}$} & \multicolumn{2}{|c|}{$\begin{array}{l}\text { Resistant coagulase- } \\
\text { negative staphylococci } \\
\qquad(n=26)\end{array}$} \\
\hline & & $n$ & $\%$ & $n$ & $\%$ \\
\hline 1 & Penicillin G (10 IU) & 42 & 95.5 & 23 & 88.5 \\
\hline 2 & Ampicillin $(10 \mu \mathrm{g})$ & 39 & 88.6 & 18 & 69.2 \\
\hline 3 & Amoxicillin/clavulanate $(30 \mu \mathrm{g})$ & 26 & 59.1 & 14 & 53.8 \\
\hline 4 & Cephalothin $(30 \mu \mathrm{g})$ & 19 & 43.2 & 11 & 42.3 \\
\hline 5 & Imipenem (10 $\mu \mathrm{g})$ & 21 & 47.7 & 5 & 19.2 \\
\hline 6 & Meropenem $(10 \mu \mathrm{g})$ & 19 & 43.2 & 3 & 11.5 \\
\hline 7 & Oxacillin $(1 \mu \mathrm{g})$ & 24 & 54.5 & 5 & 19.2 \\
\hline 8 & Cefoxitin $(30 \mu \mathrm{g})$ & 23 & 52.3 & 5 & 19.2 \\
\hline 9 & Cefepime $(30 \mu \mathrm{g})$ & 15 & 34.1 & 6 & 23.1 \\
\hline 10 & Levofloxacin $(5 \mu \mathrm{g})$ & 15 & 34.1 & 2 & 7.7 \\
\hline 11 & Ciprofloxacin $(5 \mu \mathrm{g})$ & 25 & 56.8 & 15 & 57.7 \\
\hline 12 & Erythromycin $(15 \mu \mathrm{g})$ & 29 & 65.9 & 15 & 57.7 \\
\hline 13 & Clindamycin $(10 \mu \mathrm{g})$ & 26 & 59.1 & 14 & 53.8 \\
\hline 14 & Azithromycin $(15 \mu \mathrm{g})$ & 15 & 34.1 & 12 & 46.2 \\
\hline 15 & Tetracycline $(30 \mu \mathrm{g})$ & 31 & 70.5 & 17 & 65.4 \\
\hline 16 & Rifampicin $(5 \mu \mathrm{g})$ & 6 & 13.6 & 3 & 11.5 \\
\hline 17 & Vancomycin $(30 \mu \mathrm{g})$ & 9 & 20.5 & 2 & 7.7 \\
\hline 18 & Gentamicin $(10 \mu \mathrm{g})$ & 38 & 86.4 & 15 & 57.7 \\
\hline 19 & Amikacin $(30 \mu \mathrm{g})$ & 32 & 72.7 & 14 & 53.8 \\
\hline 20 & Nitrofurantoin $(100 \mu \mathrm{g})$ & 8 & 18.2 & 4 & 15.4 \\
\hline 21 & $\begin{array}{l}\text { Trimethoprim/ } \\
\text { sulfamethoxazole }(25 \mu \mathrm{g})\end{array}$ & 28 & 63.6 & 19 & 73.1 \\
\hline
\end{tabular}

Results of antibiotic resistance profiling show that $51 / 70(72.86 \%)$ of Staphylococcus caused SSIs were of an endogenous source, $10(14.29 \%)$ were sourced from the hospital environment, and $9(12.86 \%)$ were of an undetermined source, Fig. 3b.

\section{DisCUSSION}

Despite advances in surgical technique and improved understanding of the pathogenesis of wound infections, management of SSIs represents a significant challenge to any surgical health-care facility procedure (Medeiros et al., 2005, Sattar et al., 2019). Globally, SSI rates have ranged from $2.5 \%$ to $41.9 \%$ (Mawalla et al., 2011). The rate reported in this study $(22.07 \%)$ is similar to those reported in related studies of some developing countries (Giri et al., 2013; Mezemir et al., 2020), but higher than those recorded for developed countries (Fan et al., 2014; Roumbelaki et al., 2008). In fact, the literature has mentioned that incidence rates of SSIs in developing countries may be up to 3-4 times higher than those of developed countries (Danzmann et al., 2013; Curcio et al., 2019; Mezemir et al., 2020), the difference may be due to reasons linked to patient-related and procedure-related factors including poor hospital infrastructure, poor hygiene, failure to follow-up on the patient's treatment, overwhelmed healthcare services due to population burden, and contamination from the external environment (Mukagendaneza et al., 2019; Assawapalanggool et al., 2016).

The rate of staphylococcal SSI reported in this study is in agreement with a study that revealed the predominance of
Staphylococci spp. (Rolston et al., 2014) in SSIs; however, other studies including studies conducted in Baghdad and Duhok cities have reported a lower proportion of Staphylococci spp. (Mohammed et al., 2020; Merdaw, 2011; Dessie et al., 2016). In this study, S. aureus was found to be the causative agent of more than one-third of infections and it has been found to be the single greatest cause of SSIs in the current study, as well as in the previous studies worldwide (Bhattacharya et al., 2016; Negi et al., 2015). Indeed, $S$. aureus is a widespread member of skin and nasal microbiota, with high proximity to potential surgical points of entry. During surgery, the integrity of the skin may be breached, leading to skin and soft-tissue infection by Staphylococcus spp. already inhabited on the skin of patients or found in the environment, on surgical instruments, or on the hands of health care workers (David and Daum, 2010; Reichman and Greenberg, 2009). The difference in the distribution of SSI bacteria may be due to variations in common pathogens inhabiting surgery centers, aseptic techniques, infection control and prevention policies, geographical distribution, resistance patterns of the bacterial isolates, surgical procedures performed, contamination due to poor personal hygiene or post-procedural contamination, and outbreaks (Mukagendaneza et al., 2019; Rao et al., 2013).

Most staphylococcal isolates from this study were found to be multidrug resistant. They were generally susceptible to carbapenems, rifampicin, and nitrofurantoin, but resistant to penicillinase-sensitive penicillins, tetracycline, gentamicin, and trimethoprim/sulfamethoxazole. In consistent to this finding, similar results were reported by Dessie et al., 2016. The high rate of resistance to these drugs may be attributed to the fact that these antibiotics are widely prescribed by physicians for both inpatients and outpatients to treat various bacterial infections, in addition to their relatively cheap price (Rao et al., 2013). The prophylactic use of antibiotics before and/or after surgery may induce new resistance bacteria through the transmission of resistance genes from other established bacterial species in the hospital environment and it became difficult to control (Schentag et al., 1998). The development and spread of resistant bacterial strains have emerged as a global problem. The appearance of MDR bacterial strains over the past decades has been regarded as an inevitable genetic response to the strong selective pressure imposed by antimicrobial chemotherapy (Negi et al., 2015).

More than half of $S$. aureus isolates were MRSA that were resistant to the penicillinase-resistant penicillins, oxacillin, and cefoxitin, which are similar to results reported by the previous studies on SSI isolated S. aureus (Bhattacharya et al., 2016; Khairy et al., 2011). However, it appears that this proportion cannot be generalized for SSI infections globally. For example, a study has revealed that $15.7 \%$ MRSA among SSI isolates in India (Negi et al., 2015). Surgical patients with MRSA carriage can increase the risk of SSI development; the previous study by Safdar and Bradley (2008) illustrated that patients colonized with MRSA were 4 times more likely to develop an infection than patients colonized with MSSA. It has been mentioned that the variation in the prevalence of MRSA may depend on pre- and post-operative antibiotic 
use, as well as patient surveillance programs (Bhattacharya et al., 2016). However, results of the current study were revealed that the highest proportion (88.57\%) belongs to preoperational patients' skin, nasal, and hospital environment. This was confirmed through isolation of same bacterial types from post-operative SSIs which indicates that the most significant source of MRSA is from the patients themselves.

The RAPD-PCR and UPGMA analyses revealed that the incidence rate of endogenous-sourced SSIs (including S. aureus, MRSA, and CoNS) was 3 times higher than that of exogenous sourced SSIs. Most SSIs were reported to be caused by patients' body microbiota, whereas infections caused by exogenous bacteria following surgery were less common (Skråmm et al., 2014; Leaper et al., 2008; Perl et al., 2002). S. aureus colonizes the skin and nose of human beings, and several studies have identified patients' nasal and skin $S$. aureus as a major risk factor for SSIs (Munoz et al., 2008; Liu et al., 2017; Wertheim et al., 2005). MRSA can spread from the anterior nares to other areas on the skin surface and then contaminate the surgical site (Leaper et al., 2008; Women's and Health, 2011). It has been reported that most of $S$. aureus strains are causing SSIs and they have the same identity as isolates from the nares of the patients themselves, these results were confirmed by Perl et al., 2002. In this study, the identification of the causative identities for both S. aureus and CoNS, including MRSA, and their endogenous or exogenous sources, was performed through RAPD-PCR genotyping, and involved actual matching of isolates with pre-, inter-, and post-operative isolates.

\section{CONCLUSION}

Isolation of $S$. aureus and CoNS with MDR was strongly associated with post-operative SSIs. The incidence rate of staphylococcal SSIs is high, and these SSIs including infections caused by MRSA were sourced mostly from the skin and nares of the patients themselves, rather than the surgery ward or hospital environment.

\section{REFERENCES}

Addinsoft., 2020. XLSTAT Statistical and Data Analysis Solution. Addinsoft, Boston, USA. Avilable from: https://www.xlstat.com.

Anderson, D.J. and Kaye, K.S., 2009. Staphylococcal surgical site infections. Infectious Disease Clinics of North America, 23, pp.53-72.

Assawapalanggool, S., Kasatpibal, N., Sirichotiyakul, S., Arora, R. and Suntornlimsiri, W., 2016. Risk factors for cesarean surgical site infections at a Thai-Myanmar border hospital. American Journal of Infection Control, 44, pp.990-995.

Berríos-Torres, S.I., Umscheid, C.A., Bratzler, D.W., Leas, B., Stone, E.C., Kelz, R.R., Reinke, C.E., Morgan, S., Solomkin, J.S. and Mazuski, J.E. 2017. Centers for disease control and prevention guideline for the prevention of surgical site infection, 2017. JAMA Surgery, 152, pp.784-791.

Bhattacharya, S., Pal, K., Jain, S., Chatterjee, S.S. and Konar, J., 2016. Surgical site infection by methicillin resistant Staphylococcus aureus-On decline? Journal of Clinical and Diagnostic Research, 10, p.DC32.

Burnie, J., Naderi-Nasab, M., Loudon, K. and Matthews, R., 1997. An epidemiological study of blood culture isolates of coagulase-negative staphylococci demonstrating hospital-acquired infection. Journal of Clinical Microbiology, 35, pp.1746-1750.

Byrne, F.J., Waters, S.M., Waters, P.S., Curtin, W. and Kerin, M., 2007. Development of a molecular methodology to quantify Staphylococcus epidermidis in surgical washout samples from prosthetic joint replacement surgery. European Journal of Orthopaedic Surgery and Traumatology, 17, pp.449-456.

Casey, A., Worthington, T., Caddick, J., Hilton, A., Lambert, P. and Elliott, T., 2006. RAPD for the typing of coagulase-negative staphylococci implicated in catheter-related bloodstream infection. Journal of Infection, 52, pp.282-289.

Cheadle, W.G., 2006. Risk factors for surgical site infection. Surgical Infections, 7, pp.s7-s11.

Curcio, D., Cane, A., Fernández, F. and Correa, J., 2019. Surgical site infection in elective clean and clean-contaminated surgeries in developing countries. International Journal of Infectious Diseases, 80, pp.34-45.

Dancer, S. J., Stewart, M., Coulombe, C., Gregori, A. and Virdi, M., 2012. Surgical site infections linked to contaminated surgical instruments. Journal of Hospital Infection, 81, pp.231-238.

Danzmann, L., Gastmeier, P., Schwab, F. and Vonberg, R.P., 2013. Health care workers causing large nosocomial outbreaks: A systematic review. $B M C$ Infectious Diseases, 13, p.98.

David, M.Z., \& Daum, R.S., 2010. Community-associated methicillin-resistant Staphylococcus aureus: Epidemiology and clinical consequences of an emerging epidemic. Clinical Microbiology Reviews, 23, pp.616-687.

Dessie, W., Mulugeta, G., Fentaw, S., Mihret, A., Hassen, M. and Abebe, E., 2016. Pattern of bacterial pathogens and their susceptibility isolated from surgical site infections at selected referral hospitals, Addis Ababa, Ethiopia. International Journal of Microbiology, 2016, 2418902.

Dohmen, P.M., 2006. Influence of skin flora and preventive measures on surgical site infection during cardiac surgery. Surgical Infections, 7, pp.s13-s17.

Elmer, W., Stephen, D., William, M., Paul, C. and Washington, C., 1997. Color Atlas and Textbook of Diagnostic Microbiology. Lippincott, Philadelphia, PA.

Fan, Y., Wei, Z., Wang, W., Tan, L., Jiang, H., Tian, L., Cao, Y. and Nie, S., 2014. The incidence and distribution of surgical site infection in mainland China: A meta-analysis of 84 prospective observational studies. Scientific Reports, 4, p.6783.

Forbes, B.A., Sahm, D.F. and Weissfeld, A.S., 2007. Diagnostic Microbiology. Mosby, St Louis.

Giri, S., Kandel, B.P., Pant, S., Lakhey, P.J., Singh, Y.P. and Vaidya, P., 2013. Risk factors for surgical site infections in abdominal surgery: A study in nepal. Surgical Infections, 14, pp.313-318.

Horan, T.C., Gaynes, R.P., Martone, W.J., Jarvis, W.R. and Emori, T.G., 1992. CDC definitions of nosocomial surgical site infections, 1992: A modification of $\mathrm{CDC}$ definitions of surgical wound infections. Infection Control and Hospital Epidemiology, 13, pp.606-608.

Khairy, G.A., Kambal, A.M., Al-Dohayan, A.A., Al-Shehri, M.Y., Zubaidi, A.M., Al-Naami, M.Y., Alsaif, F.A., Al-Obaid, O.A., Al-Saif, A.A. and El-Farouk, O.Y., 2011. Surgical site infection in a teaching hospital: A prospective study. Journal of Taibah University Medical Sciences, 6, pp.114-120.

Kim, J., Hong, J., Lim, J.A., Heu, S. and Roh, E., 2018. Improved multiplex PCR primers for rapid identification of coagulase-negative staphylococci. Archives of Microbiology, 200, pp.73-83.

Lane, D., 1991. 16S/23S rRNA sequencing. In: Nucleic Acid Techniques in Bacterial Systematics. John Wiley and Sons, New York, pp.115-175.

Leaper, D., Burman-Roy, S., Palanca, A., Cullen, K., Worster, D., GautamAitken, E. and Whittle, M., 2008. Prevention and treatment of surgical site infection: Summary of NICE guidance. BMJ, 337, p.a1924.

Liu, Z., Norman, G., Iheozor $\square$ Ejiofor, Z., Wong, J. K., Crosbie, E.J. and 
Wilson, P., 2017. Nasal decontamination for the prevention of surgical site infection in Staphylococcus aureus carriers. Cochrane Database of Systematic Reviews, 5(5), p.CD012462.

Magiorakos, A.P., Srinivasan, A., Carey, R., Carmeli, Y., Falagas, M., Giske, C., Harbarth, S., Hindler, J., Kahlmeter, G. and Olsson-Liljequist, B., 2012. Multidrug-resistant, extensively drug-resistant and pandrug-resistant bacteria: An international expert proposal for interim standard definitions for acquired resistance. Clinical Microbiology and Infection, 18, pp.268-281.

Mangram, A.J., Horan, T.C., Pearson, M.L., Silver, L.C. and Jarvis, W.R. 1999. Guideline for prevention of surgical site infection, 1999. Infection Control and Hospital Epidemiology, 20, pp.247-280.

Marsou, R., Bes, M., Brun, Y., Boudouma, M., Idrissi, L., Meugnier, H., Freney, J. and Etienne, J., 2001. Molecular techniques open up new vistas for typing of coagulase-negative staphylococci. Pathologie Biologie, 49, pp.205-215.

Martineau, F., Picard, F.J., Roy, P.H., Ouellette, M. and Bergeron, M.G., 1998. Species-specific and ubiquitous-DNA-based assays for rapid identification of Staphylococcus aureus. Journal of Clinical Microbiology, 36, pp.618-623.

Mawalla, B., Mshana, S.E., Chalya, P.L., Imirzalioglu, C. and Mahalu, W., 2011. Predictors of surgical site infections among patients undergoing major surgery at Bugando Medical Centre in Northwestern Tanzania. BMC Surgery, 11, p.21.

Medeiros, A.C., Aires-Neto, T., Azevedo, G.D., Vilar, M.J.P., Pinheiro, L.A.M. and Brandão-Neto, J., 2005. Surgical site infection in a university hospital in Northeast Brazil. Brazilian Journal of Infectious Diseases, 9, pp.310-314.

Merdaw, M.A., 2011. postoperative wound infections and the antimicrobial susceptibility in Baghdad Hospitals. Iraqi Journal of Pharmaceutical Sciences, 20, pp.59-65.

Mezemir, R., Seid, A., Gishu, T., Demas, T. and Gize, A., 2020. Prevalence and root causes of surgical site infections at an academic trauma and burn center in Ethiopia: A cross-sectional study. Patient Safety in Surgery, 14, p.3.

Mohammed, A.A., Hussein, N.R., Arif, S.H. and Daniel, S., 2020. Surgical site infection among patients with Staphylococcus aureus nasal carriage. International Journal of Surgery Open, 24, pp.1-7.

Mukagendaneza, M.J., Munyaneza, E., Muhawenayo, E., Nyirasebura, D., Abahuje, E., Nyirigira, J., Harelimana, J.D.D., Muvunyi, T.Z., Masaisa, F. and Byiringiro, J.C., 2019. Incidence, root causes, and outcomes of surgical site infections in a tertiary care hospital in Rwanda: A prospective observational cohort study. Patient Safety in Surgery, 13, p.10.

Munoz, P., Hortal, J., Giannella, M., Barrio, J., Rodríguez-Créixems, M., Pérez, M., Rincón, C. and Bouza, E., 2008. Nasal carriage of S. aureus increases the risk of surgical site infection after major heart surgery. Journal of Hospital Infection, 68, pp.25-31.

Negi, V., Pal, S., Juyal, D., Sharma, M.K. and Sharma, N., 2015. Bacteriological profile of surgical site infections and their antibiogram: A study from resource constrained rural setting of Uttarakhand state, India. Journal of Clinical and Diagnostic Research, 9, p.DC17.

Owens, C. and Stoessel, K., 2008. Surgical site infections: Epidemiology, microbiology and prevention. Journal of Hospital Infection, 70, pp.3-10.

Pal, S., Sayana, A., Joshi, A. and Juyal, D., 2019. Staphylococcus aureus:
A predominant cause of surgical site infections in a rural healthcare setup of Uttarakhand. Journal of Family Medicine and Primary Care, 8, p.3600.

Pereira, M., Leal, N.C., Leal, T., Sobreira, M., de Almeida, A., Siqueira $\square$ Júnior, J. and Campos $\square$ Takaki, G., 2002. Typing of human and bovine Staphylococcus aureus by RAPD $\square \mathrm{PCR}$ and ribotyping $\square \mathrm{PCR}$. Letters in Applied Microbiology, 35 , pp.32-36.

Perl, T.M., Cullen, J.J., Wenzel, R.P., Zimmerman, M.B., Pfaller, M.A., Sheppard, D., Twombley, J., French, P.P., Herwaldt, L.A. and Mupirocin And The Risk Of Staphylococcus Aureus Study Team. 2002. Intranasal mupirocin to prevent postoperative Staphylococcus aureus infections. New England Journal of Medicine, 346, pp.1871-1877.

Rao, R., Sumathi, S., Anuradha, K., Venkatesh, D. and Krishna, S., 2013. Bacteriology of postoperative wound infections. International Journal of Pharmacy and Biomedical Research, 4, pp.72-76.

Reichman, D.E. and Greenberg, J.A., 2009. Reducing surgical site infections: A review. Reviews in Obstetrics and Gynecology, 2, p.212.

Rolston, K.V., Nesher, L. and Tarrand, J.T., 2014. Current microbiology of surgical site infections in patients with cancer: A retrospective review. Infectious Diseases and Therapy, 3, pp.245-256.

Roumbelaki, M., Kritsotakis, E.I., Tsioutis, C., Tzilepi, P. and Gikas, A., 2008. Surveillance of surgical site infections at a tertiary care hospital in Greece: Incidence, risk factors, microbiology, and impact. American Journal of Infection Control, 36, pp.732-738.

Safdar, N. and Bradley, E.A., 2008. The risk of infection after nasal colonization with Staphylococcus aureus. The American Journal of Medicine, 121, pp. 310-315.

Sattar, F., Sattar, Z. and Zaman, S.A.M., 2019. Frequency of post-operative surgical site infections in a Tertiary care hospital in Abbottabad, Pakistan. Cureus, 11, e4243.

Schentag, J.J., Hyatt, J.M., Carr, J.R., Paladino, J.A., Birmingham, M.C., Zimmer, G.S. and Cumbo, T.J., 1998. Genesis of methicillin-resistant Staphylococcus aureus (MRSA), how treatment of MRSA infections has selected for vancomycinresistant Enterococcus faecium, and the importance of antibiotic management and infection control. Reviews of Infectious Diseases, 26, pp.1204-1214.

Skråmm, I., Moen, A.E.F., Årøen, A. and Bukholm, G., 2014. Surgical site infections in orthopaedic surgery demonstrate clones similar to those in orthopaedic Staphylococcus aureus nasal carriers. JBJS, 96, pp.882-888.

Wayne., 2017. M100-S27: Performance Standards for Antimicrobial Susceptibility Testing. Clinical and Laboratory Standards Institute, Wayne, PA.

Welsh, A., National Collaborating Centre for Women's and Children's Health (Great Britain)., 2011. Surgical Site Infection: Prevention and Treatment of Surgical Site Infection. RCOG Press.

Wertheim, H.F., Melles, D.C., Vos, M.C., Van Leeuwen, W., Van Belkum, A., Verbrugh, H.A. and Nouwen, J.L., 2005. The role of nasal carriage in Staphylococcus aureus infections. The Lancet Infectious Diseases, 5, pp.751-762.

WHO., 2016. Global Guidelines for the Prevention of Surgical Site Infection. World Health Organization, Geneva. 